\title{
Validation of Tubala as Appropriate Internal Control for Normalization of Gene Expression Analysis during Mouse Lung Development
}

\author{
Aditi Mehta ${ }^{1,2,3}$, Stephanie Dobersch ${ }^{1,2,3}$, Reinhard H. Dammann ${ }^{2,3,4}$, Saverio Bellusci ${ }^{2,3,5,6}$, \\ Olga N. Ilinskaya ${ }^{6}$, Thomas Braun ${ }^{2,3,7}$ and Guillermo Barreto ${ }^{1,2,3,6, *}$
}

1 LOEWE Research Group Lung Cancer Epigenetic, Max-Planck-Institute for Heart and Lung Research, Parkstraße 1, 61231 Bad Nauheim, Germany; E-Mails: aditi.mehta@mpi-bn.mpg.de (A.M.); stephanie.dobersch@mpi-bn.mpg.de (S.D.)

2 Universities of Giessen and Marburg Lung Center (UGMLC), Aulweg 130, 35392 Giessen, Germany; E-Mails: reinhard.dammann@gen.bio.uni-giessen.de (R.H.D.); Saverio.Bellusci@innere.med.uni-giessen.de (S.B.); Thomas.Braun@mpi-bn.mpg.de (T.B.)

3 German Center of Lung Research (DZL), Aulweg 130, 35392 Giessen, Germany

4 Institute for Genetics, Justus-Liebig-University, Heinrich-Buff-Ring 58, 35392 Giessen, Germany

5 Chair for Lung Matrix Remodeling, Excellence Cluster Cardio Pulmonary System, Aulweg 130, 35392 Giessen, Germany

6 Institute of Fundamental Medicine and Biology, Kazan (Volga Region) Federal University, 18 Kremlyovskaya St, 420008 Kazan, Russian Federation; E-Mail: Olga.Ilinskaya@ksu.ru

7 Department of Cardiac Development and Remodeling, Max-Planck-Institute for Heart and Lung Research, Parkstraße 1, 61231 Bad Nauheim, Germany

* Author to whom correspondence should be addressed; E-Mail: guillermo.barreto@mpi-bn.mpg.de; Tel.: +49-6032-705-259; Fax: +49-6032-705-211.

Academic Editor: William Chi-shing Cho

Received: 8 December 2014 / Accepted: 15 February 2015 / Published: 25 February 2015

\begin{abstract}
The expression ratio between the analysed gene and an internal control gene is the most widely used normalization method for quantitative RT-PCR (qRT-PCR) expression analysis. The ideal reference gene for a specific experiment is the one whose expression is not affected by the different experimental conditions tested. In this study, we validate the applicability of five commonly used reference genes during different stages of mouse lung development. The stability of expression of five different reference genes (Tubala, Actb Gapdh, Rn18S and Hist4h4) was calculated within five experimental groups
\end{abstract}


using the statistical algorithm of geNorm software. Overall, Tubala showed the least variability in expression among the different stages of lung development, while Hist $4 \mathrm{~h} 4$ and $R n 18 S$ showed the maximum variability in their expression. Expression analysis of two lung specific markers, surfactant protein $\mathrm{C}(S f t p C)$ and Clara cell-specific $10 \mathrm{kDA}$ protein $(S c g b 1 a 1)$, normalized to each of the five reference genes tested here, confirmed our results and showed that incorrect reference gene choice can lead to artefacts. Moreover, a combination of two internal controls for normalization of expression analysis during lung development will increase the accuracy and reliability of results.

Keywords: mouse lung development; reference gene; qRT-PCR; geNorm; alpha 1A tubulin; Tubala

\section{Introduction}

Quantification of transcript levels constitutes one of the crucial aspects of characterizing samples in molecular biology. Techniques to analyse gene expression include reverse transcription followed by polymerase chain reaction (RT-PCR), Northern Blotting, in situ hybridization and microarray-based expression analysis. Due to several reasons, use of quantitative PCR to amplify cDNA reverse transcribed from RNA (qRT-PCR) became a routine tool and is the most common technique. Quantitative RT-PCR is cost-efficient and uncomplicated to perform, allowing rapid throughput. In addition, qRT-PCR provides the specificity that is required for accurate and reliable quantification results. Finally, qRT-PCR is highly sensitive and permits the detection of rare transcripts and small changes in gene expression. Even a single cell has been used for qRT-PCR based expression analysis [1].

Our study deals with the relative quantification of gene expression by qRT-PCR. One of the critical aspects of relative gene expression analysis is normalization. Several strategies have been proposed to normalize the analysis of transcript levels, including similar starting material based on sample size or tissue volume, cell numbers, amount of total RNA or genomic DNA, use of external RNA as a "spike-in" standard [2] and comparison with an endogenous reference gene transcript [3,4]. A combination of two or more of these normalization strategies is frequently used to increase the reliability of the data. However, the expression ratio between the analysed gene and an internal control gene is the most widely used normalization method. Importantly, correct choice of the reference gene is critical to this normalization method, since incorrect reference gene choice can lead to artefacts [5]. The ideal reference gene for a specific experiment is the one whose expression is not affected by the different experimental conditions tested. Thus it is highly recommended to validate the selected reference gene for each experimental set up. In this study, we addressed this issue, focusing on mouse lung development.

The mouse lung originates from the anterior endoderm and forms during five phases of lung development: embryonic (9.5 to 12.5 days post coitum; E9.5-E12.5), pseudoglandular (E12.5-E16.5), canalicular (E16.5-E17.5), saccular (E17.5 to 5 days after birth; E17.5-P5) and alveolar (P5-P28) [6-8]. At the end of the embryonic phase, primary and secondary lung bud formation has taken place and the embryonic lung consists of one left lobe and four right lobes. From E10.5 to E16.5, the epithelium 
undergoes branching morphogenesis to form the respiratory (bronchial) tree. In parallel to branching morphogenesis, the primitive lung epithelium differentiates to several specialized cell types. However, most of the differentiation occurs in the canalicular and saccular phases (E16.5-P5). We have selected five of the most commonly used genes as reference for normalization of expression analysis during mouse lung development in previous reports [9] (Table 1). These genes have been involved in different cellular processes, alpha 1a tubulin (Tubala) and beta actin (Actb) are both required for cellular cytoskeleton [10]; glyceraldehyde 3 phosphate dehydrogenase (Gapdh) is a key enzyme in the control of glycolysis [5,11]; histone H4 (Hist4h4) is central to nucleosome formation [12] and 18S ribosomal RNA $(R n 18 S)$ is a structural component of eukaryotic ribosomes [13]. The objective of this study was to determine the validity of these genes as endogenous controls for the normalization of qRT-PCR-based expression analysis during the different phases of mouse lung development.

Our work is the first exhaustive study to validate internal controls for expression analysis through lung development. The relevance of our work was demonstrated by changing the results of qRT-PCR expression analysis for two epithelial markers during lung development when inappropriate reference genes were used for normalization. Proper verification and subsequent selection of suitable endogenous controls for a specific experimental setup will prevent inadequate quantification. The stability of expression of an internal control is required for accurate and reliable normalization in expression analysis experiments.

\section{Results}

\subsection{Design of Primer Pairs for qRT-PCR Expression Analysis of Reference Genes that Are Widely Used in Mouse Lung Development}

Primer pairs for qRT-PCR-based expression analysis of the genes chosen for the present study were designed using the Geneious software [14] (Table 1). Primer pairs for Tubala, Actb and Gapdh were spanning an intron (Figure 1) to avoid artefacts produced by leftovers of genomic DNA or precursor mRNA during quantitative PCR amplification of cDNA after reverse transcription from RNA. The primer pairs for Hist4h4 and Rn18S were located in one exon due to their gene structure. A nucleotide BLAST (Basic Local Alignment Search Tool) search of the mouse RefSeq RNA database using the sequence of the designed primers as query revealed that the selected primer pairs specifically bind to their respective target transcripts and amplify only a single amplicon of the expected length, as supported by NCBI $E$-values lower than 0.05 (Table 2). In addition, the primer pairs were designed in order to amplify any known transcript variants or isoforms of their respective target. Interestingly, the analysis for $A c t b$ revealed that the mRNA sequence shares $91 \%$ homology with $L r r c 58$ (leucine rich repeat containing 58). Thus, primer pairs were designed such that only the specific amplicon of Actb was obtained. Further, using the tool jPCR [15] and the Sigma Aldrich Oligo Evaluator online tool, it was confirmed that the primer pairs did not form primer dimers, had a similar annealing temperature, amplified amplicons of comparable length (between 151 and 312 base pairs) and did not form secondary structures for all the genes analysed in this study (Table 2). 
Table 1. Internal control genes evaluated in this study.

\begin{tabular}{|c|c|c|c|c|c|}
\hline Gene Symbol & Accession & Name & Function & Localization & Pseudogenes ${ }^{\dagger}$ \\
\hline Tubala & NM_011653 & tubulin, alpha $1 \mathrm{~A}$ & Essential for structure and kinetics of cytoskeleton & Chr $15(15 \mathrm{~F} 1 ; 1555.29 \mathrm{cM})$ & 3 \\
\hline Actb & NM_007393 & actin, beta & Essential for structure and kinetics of cytoskeleton & Chr $5(5 \mathrm{G} 2 ; 581.8 \mathrm{cM})$ & 39 \\
\hline Gapdh & NM_008084 & $\begin{array}{c}\text { glyceraldehyde-3-phosphate } \\
\text { dehydrogenase }\end{array}$ & Important enzyme of glycolytic pathway & Chr 6 (6 F2; $659.32 \mathrm{cM})$ & 309 \\
\hline Hist4h4 & NM_175652 & histone cluster $4, \mathrm{H} 4$ & Structural component of nucleosome & Chr $6(6$ G1; 6) & 0 \\
\hline$R n 18 S$ & NR_003278 & $18 \mathrm{~S}$ ribosomal RNA & Ribosomal subunits & Chr $6(6 ; 17)$ & 1 \\
\hline
\end{tabular}

Table 2. Primers for internal control genes.

\begin{tabular}{|c|c|c|c|c|c|c|c|c|c|c|c|c|}
\hline $\begin{array}{c}\text { Gene } \\
\text { Symbol } \\
\end{array}$ & $\begin{array}{c}\text { Forward Primer } \\
\left(5^{\prime}-3^{\prime}\right) \\
\end{array}$ & $\operatorname{Tm}\left({ }^{\circ} \mathrm{C}\right)$ & $E$ Value & $\begin{array}{c}\text { Reverse Primer } \\
\left(5^{\prime}-3^{\prime}\right) \\
\end{array}$ & $\operatorname{Tm}\left({ }^{\circ} \mathbf{C}\right)$ & $E$ Value & $\begin{array}{l}\text { Primer } \\
\text { Dimer }\end{array}$ & $\begin{array}{l}\text { Secondary } \\
\text { Structure }\end{array}$ & $\begin{array}{c}\text { Intron } \\
\text { Spanning } \\
\end{array}$ & $\begin{array}{c}\text { Amplicon } \\
\text { Size } \\
\end{array}$ & $\begin{array}{c}\text { Slope } \\
(\mathbf{R}>\mathbf{0 . 9 9})^{\dagger} \\
\end{array}$ & $\begin{array}{c}\text { Amplification } \\
\text { Efficiency (\%) }\end{array}$ \\
\hline Tubala & $\begin{array}{l}\text { CCGCGAAGC } \\
\text { AGCAACCAT }\end{array}$ & 61.43 & 0.012 & $\begin{array}{l}\text { CCAGGTCTAC } \\
\text { GAACACTGCC }\end{array}$ & 60.39 & 0.001 & No & None & Yes & 227 & -3.3711 & 97.36 \\
\hline$A c t b$ & $\begin{array}{c}\text { ACACCCGCC } \\
\text { ACCAGTTC }\end{array}$ & 64.78 & 0.032 & $\begin{array}{l}\text { TACAGCCCG } \\
\text { GGGAGCAT }\end{array}$ & 62.21 & 0.032 & No & Very weak & Yes & 110 & -3.3797 & 97.64 \\
\hline Gapdh & $\begin{array}{c}\text { TGAGTATGTCG } \\
\text { TGGAGTCTAC }\end{array}$ & 56.33 & $4 \times 10^{-4}$ & $\begin{array}{c}\text { TGGACTGTGG } \\
\text { TCATGAGCC }\end{array}$ & 59.32 & 0.004 & No & None & Yes & 261 & -3.3904 & 97.22 \\
\hline HistH4 & $\begin{array}{c}\text { ATGTCAGGACG } \\
\text { AGGAAAAGGC }\end{array}$ & 60.34 & $4 \times 10^{-4}$ & $\begin{array}{l}\text { TTAGCCGCCG } \\
\text { AAGCCGTAC }\end{array}$ & 62.70 & 0.004 & No & None & No & 312 & -3.4822 & 99.17 \\
\hline$R n 18 S$ & $\begin{array}{l}\text { GTAACCCGTT } \\
\text { GAACCCCATT }\end{array}$ & 58.1 & 0.013 & $\begin{array}{l}\text { CCATCCAATC } \\
\text { GGTAGTAGCG }\end{array}$ & 57.93 & 0.013 & & None & No & 151 & -3.4239 & 95.91 \\
\hline
\end{tabular}

$\dagger$ Slope of the linear regression line along the coefficient of regression, R, analysed by triplicate qRT-PCR reactions; ${ }^{\star}$ Amplification efficiency calculated using the formula, $E=10^{(-1 / \text { Slope })}-1 ; \cdot$ Based on $\Delta G$ calculations at $45^{\circ} \mathrm{C}$. 


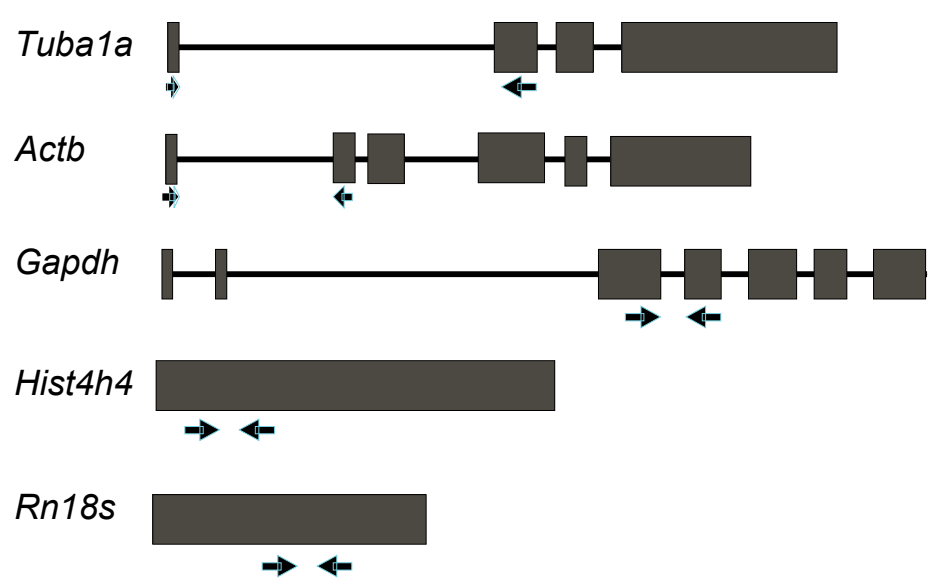

Figure 1. Gene structure of markers commonly used as internal controls for expression analysis during mouse lung development. Schematic representation of the gene structure of commonly used reference genes for expression analysis. Exons are represented as grey boxes and introns as black lines, while primer binding sites are shown with arrows.

\subsection{Characterization of Primer Pairs by Determining the Amplification Efficiency and through} Dissociation Curve Analysis

Optimal primer pair design achieves doubling of the specific PCR product after each cycle of the PCR reaction during the exponential phase of amplification. In this ideal situation, the amplification efficiency of the primer pair would be $100 \%$ and the qRT-PCR results can be analysed using the $2^{(-\Delta \Delta C T)}$ method [16]. We decided to determine the amplification efficiency of the primer pairs that we designed for each one of the genes analysed in this study (Figure 2). Therefore we have performed qPCRs using the different primer pairs and, as a template, tenfold serial dilutions of a cDNA mixture of known concentration. The results of these qPCRs were used to elaborate a standard curve for each one of the primer pairs by plotting the template quantity $\left(\log _{10} ; x\right.$-axis $)$ against the threshold cycle $\left(C_{\mathrm{T}}\right.$; $y$-axis) (Figure 2A). The resulting standard curves can be described by the function $y=\mathrm{m} x+\mathrm{c}$, where $\mathrm{m}$ is the slope of the line, $\mathrm{c}$ is the $y$-axis intercept and $x$ is the independent variable of the function $y=f(x)$ The amplification efficiency $(E)$ of each primer pair was calculated using the slope of the standard curve and the formula, $E=\left(10^{(-1 / \text { Slope })}-1\right) \times 100 \%$ [17] (Table 2). Four of the five primer pairs analysed in this study had amplification efficiencies above 97\%. Only the primer pair for Rn $18 S$ showed an amplification efficiency of $95.9 \%$. However, the amplification efficiency of all the primer pairs analysed here was within the acceptable range of $100 \% \pm 10 \%$ [18]. In addition, the dissociation curve analysis of the different qRT-PCR products showed a single peak for each one of the genes (Figure 2B), confirming the absence of non-specific PCR products, primer dimers or secondary structures [19]. Further, agarose gel electrophoresis after qRT-PCR demonstrated a single band of the expected size only in the sample containing the template, while no product was obtained in the negative controls without reverse transcriptase (-RT) or with water (Figure $2 \mathrm{C}$ ), confirming again the specificity of the primer pairs and the absence of genomic DNA contamination. Lastly, sequencing of the PCR products obtained from each of the reactions confirmed the identity of the amplicons and the specificity of the analysis (Figure 3). For Tubala, Actb, Gapdh and Rn18S, all the five clones showed specificity to the intended product. However, for Hist4h4, Clone 5 showed only $88 \%$ homology to the target. 
This can be explained by the fact that the histone cluster genes are highly conserved and all of them give rise to an identical Histone 4 (H4) protein. Although the designed primers were targeting Hist4h4, the primers also recognized Hist $2 \mathrm{~h} 4$, despite considerable mismatch, resulting in a product of identical size. Clone 5 was highly similar to Hist $2 \mathrm{~h} 4$, a Histone 4 variant that is encoded by Histone Cluster 2, which shows only $86 \%$ homology to HistH4h.

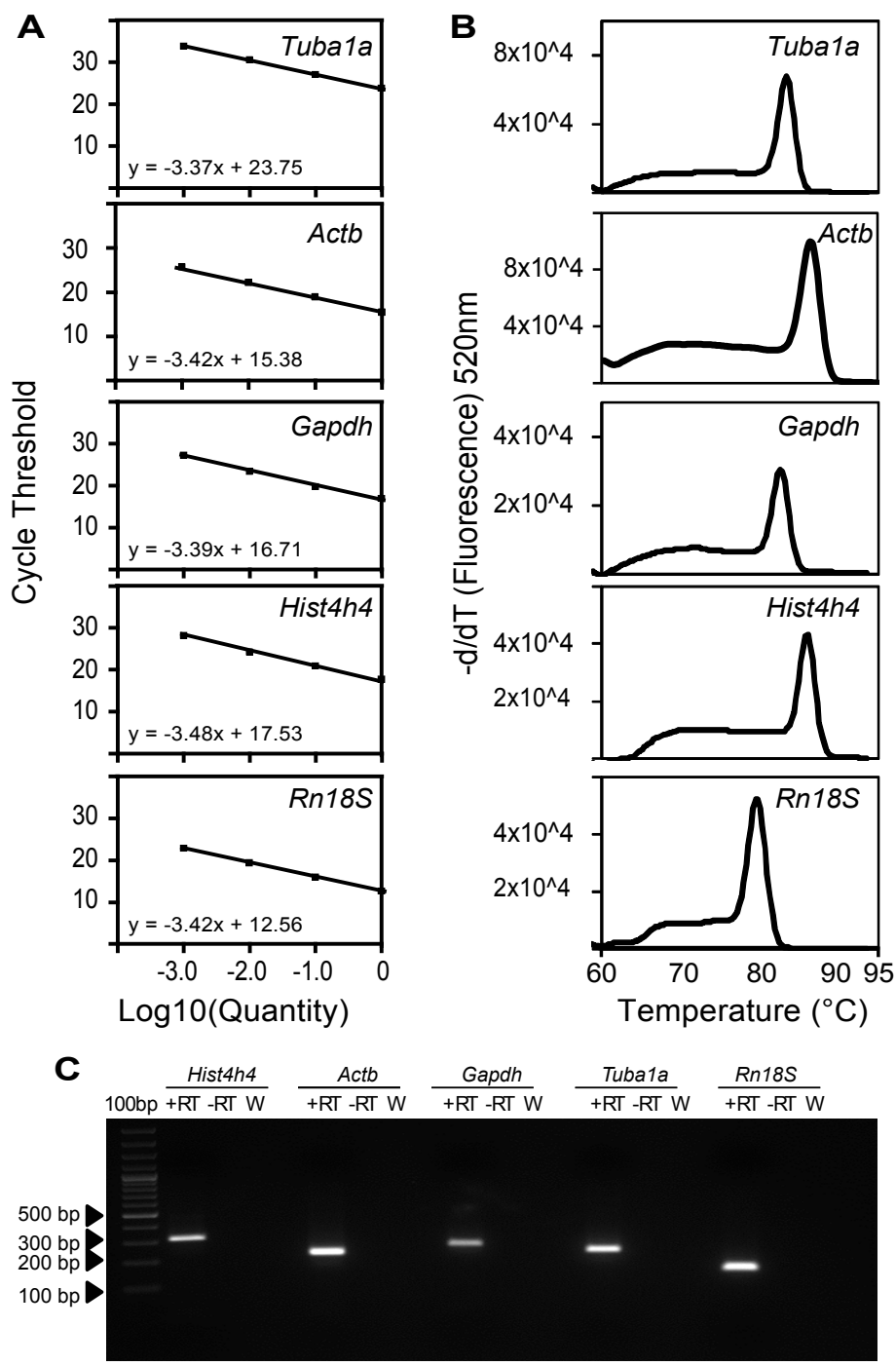

Figure 2. Characterization of primer pairs designed for expression analysis of the internal control during mouse lung development. (A) Amplification efficiency for each primer pair was calculated using 10-fold serial dilutions of a cDNA template. Primer amplification efficiency was assessed by plotting the cycle threshold $\left(C_{\mathrm{T}}\right)$ value for each concentration against the logarithm (base 10 ) of the fold dilution ( $\log _{10}$ (Quantity)). Efficiency was calculated using the slope of the linear function; (B) Dissociation curve analysis of primer specific products was performed by constantly monitoring the fluorescence with increasing temperatures from 60 to $95{ }^{\circ} \mathrm{C}$. Melt curves were generated by plotting the negative first derivative of the fluorescence $(-\mathrm{d} / \mathrm{d} T$ (Fluorescence) $520 \mathrm{~nm})$ versus temperature (degree Celsius, ${ }^{\circ} \mathrm{C}$ ); (C) Agarose gel electrophoresis after qRT-PCR indicates a specific product for each of the primer pairs. $+\mathrm{RT}$, template is cDNA; $-\mathrm{RT}$, template is RNA without reverse transcriptase, $\mathrm{W}$, water control. 
Tuba1a

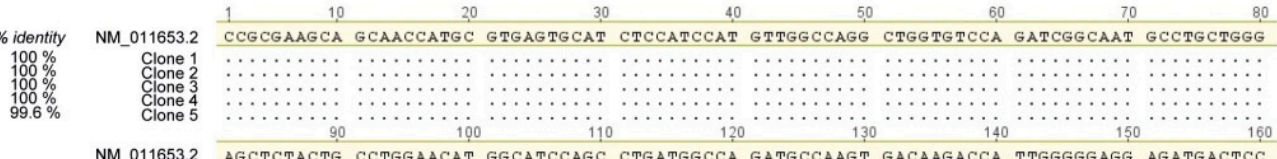

NM_011653.2 AGCTCTACTG CCTGGAACAT GGCATCCAGC CTGATGGCCA GATGCCAAGT GACAAGACCA TTGGGGGAGG AGATGACTCC

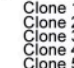

NM 011653.2 1900

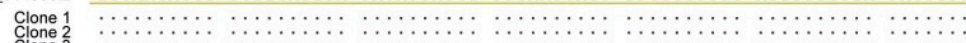

Actb

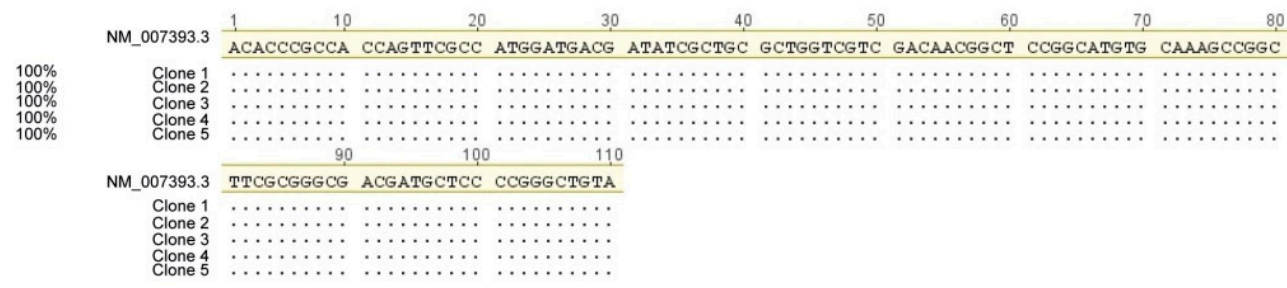

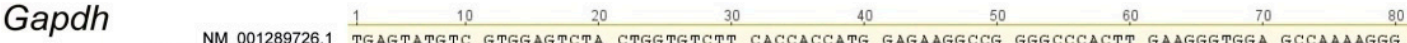
$100 \%$ NM_001289720.1 \begin{tabular}{ll}
$100 \%$ & Clone 2 \\
$100 \%$ & Clone 3 \\
$100 \%$ & Clone \\
\hline
\end{tabular}

NM_001289726.1

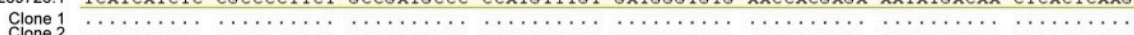
Clone 2
Clone 3
Clone 4
Clone 5

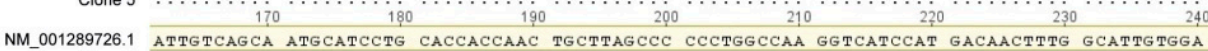
Clone
Clone 2

\begin{tabular}{l} 
Clone 2 \\
Clone 3 \\
Clone 4 \\
\hline
\end{tabular}

NM_001289726.1 AGGGCTCATG ACCACAGTCC A

Clone 1
Clone 2
Clone 3
Clone 3

Hist4h4

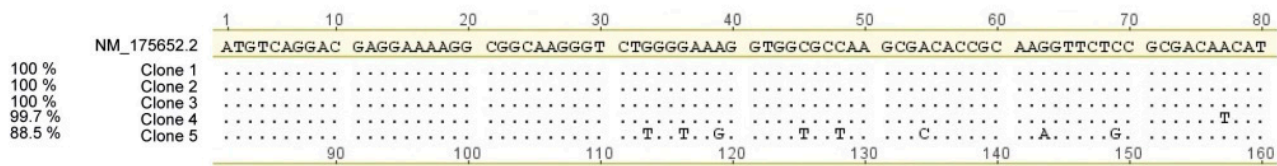

NM_175652.2 CCAGGGCATT ACCAAGCCCG CTATCCGGCG GTTGGCTCGG CGTGGCGGCG TGAAGCGCAT CTCGGGTCTC ATCTACGAGG

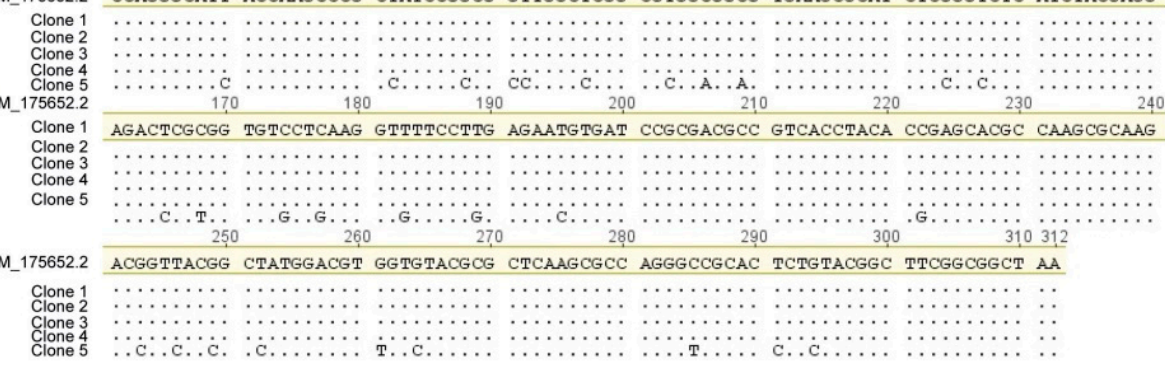

Rn18S

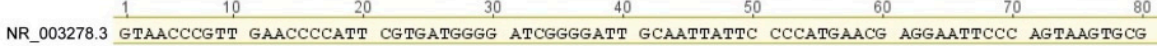

$100 \%$
$100 \%$
$100 \%$
$99.3 \%$
$99.3 \%$

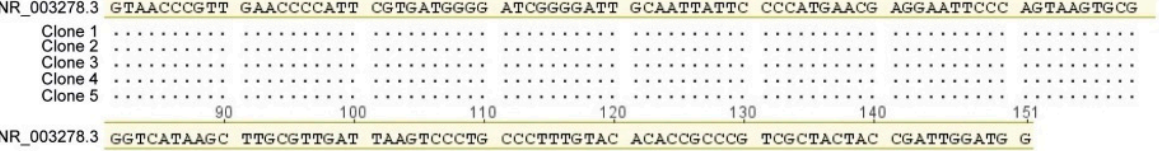

NR_003278.3 GGTCATAAGC TTGCGTTGAT TAAGTCCCTG CCCTTTGTAC ACACCGCCCG TCGCTACTAC CGATTGGATG G Clone 1
Clone 2
Clone 3
Clone 4

Figure 3. Sequence identity of the PCR products for the five reference genes evaluated in this study. Five plasmid clones (Clone 1-5) containing the PCR products of each of the reference genes evaluated in this study were compared against the reference sequence available at NCBI (Highlighted in yellow). Dots represent bases identical to the reference sequence while mismatches are indicated. Percentage of identity (\% identity) is indicated for each clone. 


\subsection{Tubala Is the Least Variable Endogenous Reference for the Normalization of qRT-PCR-Based} Expression Analysis during Mouse Lung Development

The ideal reference gene for a specific experiment, in which the relative quantification of gene expression should be determined by qRT-PCR, is the one whose expression is not affected by the different experimental conditions tested. To determine which one of the genes chosen for the present study is the most suitable as endogenous reference for the normalization of qRT-PCR-based expression analysis during mouse lung development, we have analysed their expression in an embryonic mouse lung at different days post coitum (E11.5-E18.5) and in a mouse lung at different days after birth (P1-P28) (Figure 4A). To be able to compare the qRT-PCR results obtained with the different primer pairs in the different stages of mouse lung development, we have normalized the threshold cycle $\left(C_{\mathrm{T}}\right)$ with respect to the amount of RNA used in the reverse transcription reaction. The $C_{\mathrm{T}} / \mu \mathrm{g}$ RNA values for the genes analysed here showed a wide range from 15 to 30 depending on the stage of mouse lung development and the marker analysed. Tubala showed the most the least variability in expression among the different stages of lung development, with an average $C_{\mathrm{T}} / \mu \mathrm{g}$ RNA value of 19.5 and a standard deviation of 0.45 (Figure 4B). The rest of the genes showed a higher variation in their expression level during the different lung development stages. Gapdh and Actb showed moderately higher variation with average $C_{\mathrm{T}} / \mu \mathrm{g}$ RNA of $15.94 \pm 1.25$ and $16.08 \pm 1.21$ respectively. Hist4h4 and Rnl $8 S$ had an average $C_{\mathrm{T}} / \mu \mathrm{g}$ RNA of $20.47 \pm 2.28$ and $14.5 \pm 3.05$ and were highly unstable. Our results suggest Tubala is the most appropriate reference gene for normalizing gene expression analysis during mouse lung development.
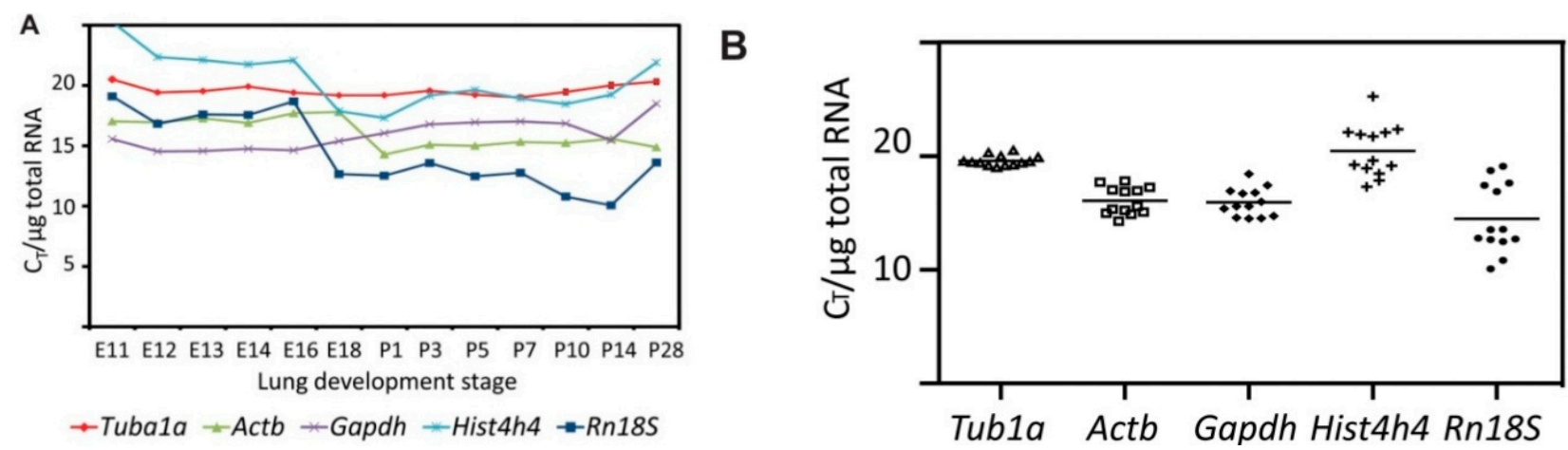

Figure 4. Expression analysis of the internal control genes evaluated in this study during different phases of lung development. (A) Variable cycle threshold $\left(C_{\mathrm{T}}\right)$ for the different reference genes over mouse lung development. $C_{\mathrm{T}}$ values were determined by qRT-PCR in triplicates for biological duplicates $(n=6)$ at the indicated stages of lung development. The $C_{\mathrm{T}}$ values were normalized to total RNA quantity used for the RT reaction. Data are represented as mean $C_{\mathrm{T}} \pm \mathrm{SD}$; (B) $C_{\mathrm{T}}$ distribution of each putative reference gene among all mouse lung development stages analysed here. $C_{\mathrm{T}}$ values were determined as in A. For each reference gene, the mean $C_{\mathrm{T}}$ for each stage (points) and the mean $C_{\mathrm{T}}$ for all stages (line) were plotted to represent $C_{\mathrm{T}}$ variation between stages of lung development.

To further confirm this finding we have applied the statistical algorithm geNorm [20] to determine the gene expression stability $(M)$ for all the putative reference genes analysed here within each of the 
groups of samples described before (Figure 5A and Table 3). Based on this approach, the reference genes analysed in this study were ranked in each sample group with respect to their $M$ value from most stable (lowest $M$ value) to least stable (highest $M$ value). Keeping in mind the large heterogeneity of the samples and the vast age-related differences, a threshold for the $M$ value of 1.0 was considered appropriate. For Group 1 (branching morphogenesis; E11.5-E16.5), the five tested reference genes showed $\mathrm{M}$ values below the threshold of 1.0 [20], indicating adequate gene expression stability to be used as internal control for normalization of qRT-PCR expression analysis for this group. Based on several reports suggesting the use of at least two different endogenous controls for the normalization of expression analysis, we calculated the normalization factors with the two most stable reference genes and systematically included additional reference genes. Pairwise variation was used to determine the optimal number of reference genes (Figure 5B, Table 4). A cut off value of 0.3 was considered optimal for the pairwise variation coefficient. For Group 1, V2/3 was 0.09 , indicating that the combination of Tubala and Gapdh is sufficient to standardize gene expression during branching morphogenesis.
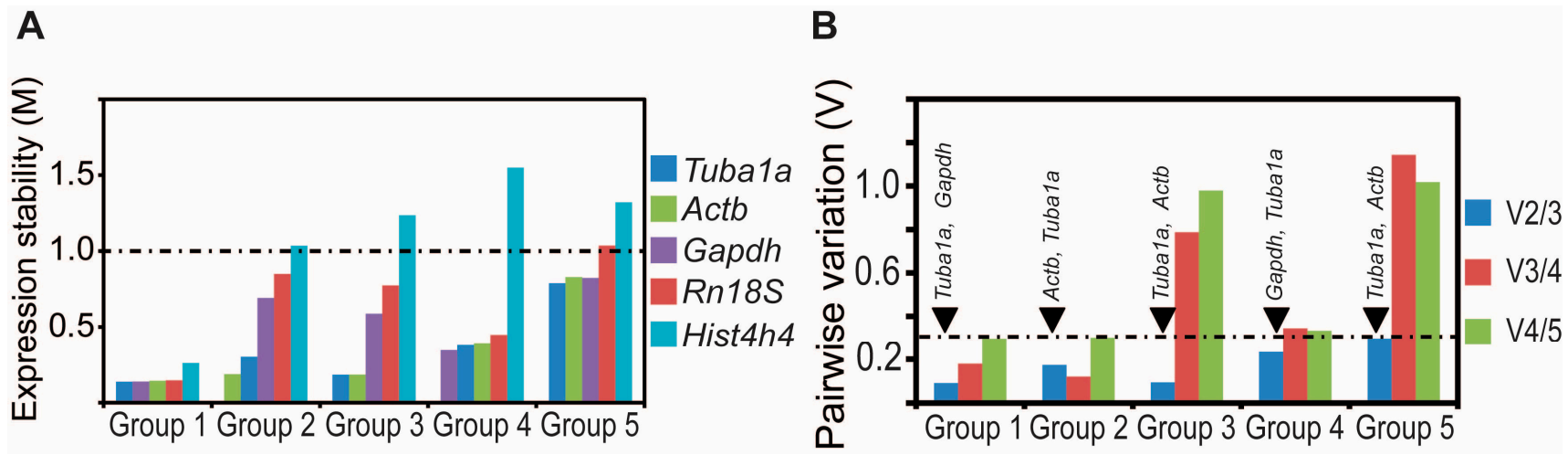

Figure 5. Calculation of average expression stability and pairwise variation coefficient for each of the putative reference genes. (A) Gene expression stability values $(M)$ of the putative reference genes were calculated for each of the five experimental groups using the geNorm statistical algorithm. A lower $M$ value indicated more stable gene expression. $M$ values below 1.0 were considered optimal. Group 1 (branching morphogenesis, E11.5-E16.5); Group 2, (canalicular and saccular phases, E16.5-P5); Group 3 (prenatal development, E11.5-E18.5); Group 4 (postnatal development, P1-P28) and Group 5 (all stages); (B) The optimal number of control genes for each experimental group was determined by geNorm by calculating the pairwise variation coefficient $\left(V_{n /(n+1)}\right)$ between two sequential normalization factors $\left(\mathrm{NF}_{n}\right.$ and $\left.\mathrm{NF}_{n+1}\right)$, where $\mathrm{n}$ is the number of genes involved in normalization factors. Values less than 0.3 were taken as optimal. Systematic inclusion of more unstable reference genes resulted in an increase in the values. Sample grouping as in (A). 
Table 3. Control genes ranked in order of their average expression stability. Reference genes are ranked according to the average expression stability value, $M$, as calculated by the geNorm statistical algorithm. The genes are ranked as most stable on the top. Group 1, branching morphogenesis (E11.5-E16.5); Group 2, differentiation, canalicular and saccular (E16.5-P5); Group 3, prenatal development (E11.5-E18.5); Group 4, postnatal development (P1-P28); Group 5, all stages.

\begin{tabular}{|c|c|c|c|c|c|c|c|c|c|}
\hline \multicolumn{2}{|r|}{ Group 1} & \multicolumn{2}{|r|}{ Group 2} & \multicolumn{2}{|r|}{ Group 3} & \multicolumn{2}{|r|}{ Group 4} & \multicolumn{2}{|r|}{ Group 5} \\
\hline Ranking & Stability Value $(M)$ & Ranking & Stability Value $(M)$ & Ranking & Stability Value $(M)$ & Ranking & Stability Value $(M)$ & Ranking & Stability Value $(M)$ \\
\hline Tubala & 0.136 & Actb & 0.185 & Tubala & 0.182 & Gapdh & 0.343 & Tubala & 0.788 \\
\hline Gapdh & 0.137 & Tubala & 0.299 & $A c t b$ & 0.183 & Tubala & 0.376 & $A c t b$ & 0.822 \\
\hline Actb & 0.142 & Gapdh & 0.691 & Gapdh & 0.586 & Actb & 0.386 & Gapdh & 0.829 \\
\hline$R n 18 S$ & 0.145 & $R n 18 S$ & 0.849 & Rn18S & 0.773 & $R n 18 S$ & 0.447 & $\operatorname{Rn} 18 S$ & 1.035 \\
\hline Hist4h4 & 0.258 & Hist4h4 & 1.035 & Hist4h4 & 1.236 & Hist4h4 & 1.55 & Hist4h4 & 1.321 \\
\hline
\end{tabular}

Table 4. Pairwise variation coefficient calculated for sequential normalization factors for each of the five experimental groups. Pairwise variation coefficient of the most stable genes was calculated followed by sequential inclusion of less stable genes. Group 1, branching morphogenesis (E11.5-E16.5); Group 2, differentiation, canalicular and saccular (E16.5-P5); Group 3, prenatal development (E11.5-E18.5); Group 4, postnatal development (P1-P28); Group 5, all stages.

\begin{tabular}{cccc}
\hline Group & $\mathbf{V 2 / 3}$ & $\mathbf{V 3 / 4}$ & $\mathbf{V 4 / 5}$ \\
\hline \multirow{2}{*}{ Group 1 } & Tubala, Gapdh & Tubala, Gapdh, Actb & Tubala, Gapdh, Rn18S \\
& 0.091462 & 0.179303 & 0.296517 \\
\hline \multirow{2}{*}{ Group 2 } & Tubala, Actb & Tubala, Gapdh, Actb & Tubala, Gapdh, Rn18S \\
& 0.173682 & 0.12009 & 0.30073 \\
\hline \multirow{2}{*}{ Group 3 } & Tubala, Actb & Tubala, Gapdh, Actb & Tubala, Gapdh, Rn18S \\
& 0.094428 & 0.786888 & 0.978725 \\
\hline \multirow{2}{*}{ Group 4 } & Tubala, Gapdh & Tubala, Gapdh, Actb & Tubala, Gapdh, Rn18S \\
& 0.234143 & 0.343936 & 0.333048 \\
\hline \multirow{2}{*}{ Group 5 } & Tubala, Actb & Tubala, Gapdh, Actb & Tubala, Gapdh, Rn18S \\
& 0.29673 & 1.143188 & 1.018239 \\
\hline
\end{tabular}


For Group 2 (cellular differentiation during canalicular and saccular phases, E16.5-P5), Actb and Tubala showed $M$ values below the threshold of 1.0 ( $M=0.185$ and 0.299 respectively). The $M$ values for Gapdh, Rn18S and Hist4h4 were $0.691,0.849$ and 1.035 respectively, thereby showing higher variability. Further, pairwise correlation analysis showed a value of 0.17 for $\mathrm{V} 2 / 3$, which indicates that a combination of $A c t b$ and Tubala is sufficient to standardize gene expression during cellular differentiation.

Similar analysis was performed for all the other experimental groups. For Group 3 (Prenatal development, E11.5-E18.5), Tubala and Actb were the most reliable reference genes, with $M$ values of 0.182 and 0.183 , respectively. The pairwise correlation showed a value of 0.094 for $\mathrm{V} 2 / 3$, indicating that a combination of Tubala and Actb may be optimal for standardization of expression analysis in Group 3. In Group 4 (Postnatal development, P1-P28), Gapdh, Tubala, Actb and Rn18S had M values below the threshold of $1.0(M=0.343,0.376,0.386$ and 0.447$)$. The pairwise variation coefficient for V2/3 was 0.234 , suggesting that a combination of Gapdh and Tubala is appropriate to use for normalization of expression analysis in Group 4. For Group 5, on including all stages of lung development, Tubala, Actb and Gapdh were the most reliable genes $(M=0.788,0.822$ and 0.829, respectively) and the pairwise variation coefficient for V2/3 (0.296) was marginally below the cut off value, thereby suggesting that a combination of Tubala and Actb may be used for normalization of expression analysis in Group 5. Our analysis further demonstrates the need to identify the most optimal reference genes for each experimental set up.

\subsection{Expression Analysis of Two Cell Lineage Markers Using Different Normalizing Genes Suggesting} Tubala Is the Most Suitable Endogenous Reference during Mouse Lung Development

From E10.5 to P5, the epithelium of the developing lung differentiates from a morphologically uniform cell population to different specialized cell types, thereby establishing a proximal-distal axis in the developing lung. The primitive lung epithelium (before E16.5) co-expresses several lineage markers including Clara cell-specific $10 \mathrm{kDa}$ protein (Scgblal, also CC10) and surfactant associated protein C (Sftpc, also SP-C). Later in gestation (E16.5 onwards), Scgblal is a marker for the proximal epithelium, whereas $S f t p c$ expression defines the distal epithelium. In the adult lung these markers are characteristic of distinct cell lineages, Scgblal of Clara cells and Sftpc of alveolar type II (ATII) cells. The expression of these two markers was determined by qRT-PCR at different stages of mouse lung development and normalized with respect to each of the reference genes chosen for this study (Figure 6). After normalization using Tubala, Actb or Gapdh as reference genes, the $\log _{10}$ transformed relative normalized expression of Sftpc and Scgblal increased from E11.5 till E16.5 and reached high levels of expression that were maintained through E18.5 to P28, consistent with previous reports [21-26]. In contrast, normalization with respect to Hist4h4 and Rn18S showed an initial increase of Sftpc expression (till E16.5) and then a subsequent drop in expression (till P28), wherein the expression levels were similar to those in embryonic lungs (E11-E14). For Scgb1a1, normalization with Rn18S showed an initial increase of expression at E16.5 followed by a drop in expression which increased again at P3. Thus, Hist4h4 or Rn18S normalization leads to altered expression profiles. These results support our previous findings (Figure 5A and Table 3) in which we have identified Tubala as the most appropriate reference gene for normalizing expression analysis during mouse lung development, followed by $A c t b$ or Gapdh depending on the phases of lung development analysed. Furthermore, $\log _{10}$ 
transformed relative normalized expression analysis of Sftpc and Scgblal using a combination of the reference genes Tubala and Actb (Figure 7) show even more consistent results than the standardization of the analysis using single reference genes, thereby supporting our results from the pairwise variation coefficient calculation (Figure 5B and Table 4), which suggest a combination of Tubala and Actb for standardization of expression analysis during lung development. The conflicting expression patterns of SftpC and Scgblal obtained after Rn18S- or Hist4h4-normalization as compared to the ones after normalization to Tubala, Actb or Gapdh alone or to a combination of Tubala and Actb highlights the importance of our analysis. Taking into consideration the complexity and the vast cellular diversity of the lung, it is crucial to validate the reference genes for every experimental setting in order to improve the consistency and to exploit the high sensitivity of qRT-PCR-based expression analysis. Inappropriate reference gene selection can result in artefacts, inaccurate interpretations and/or misleading conclusions.

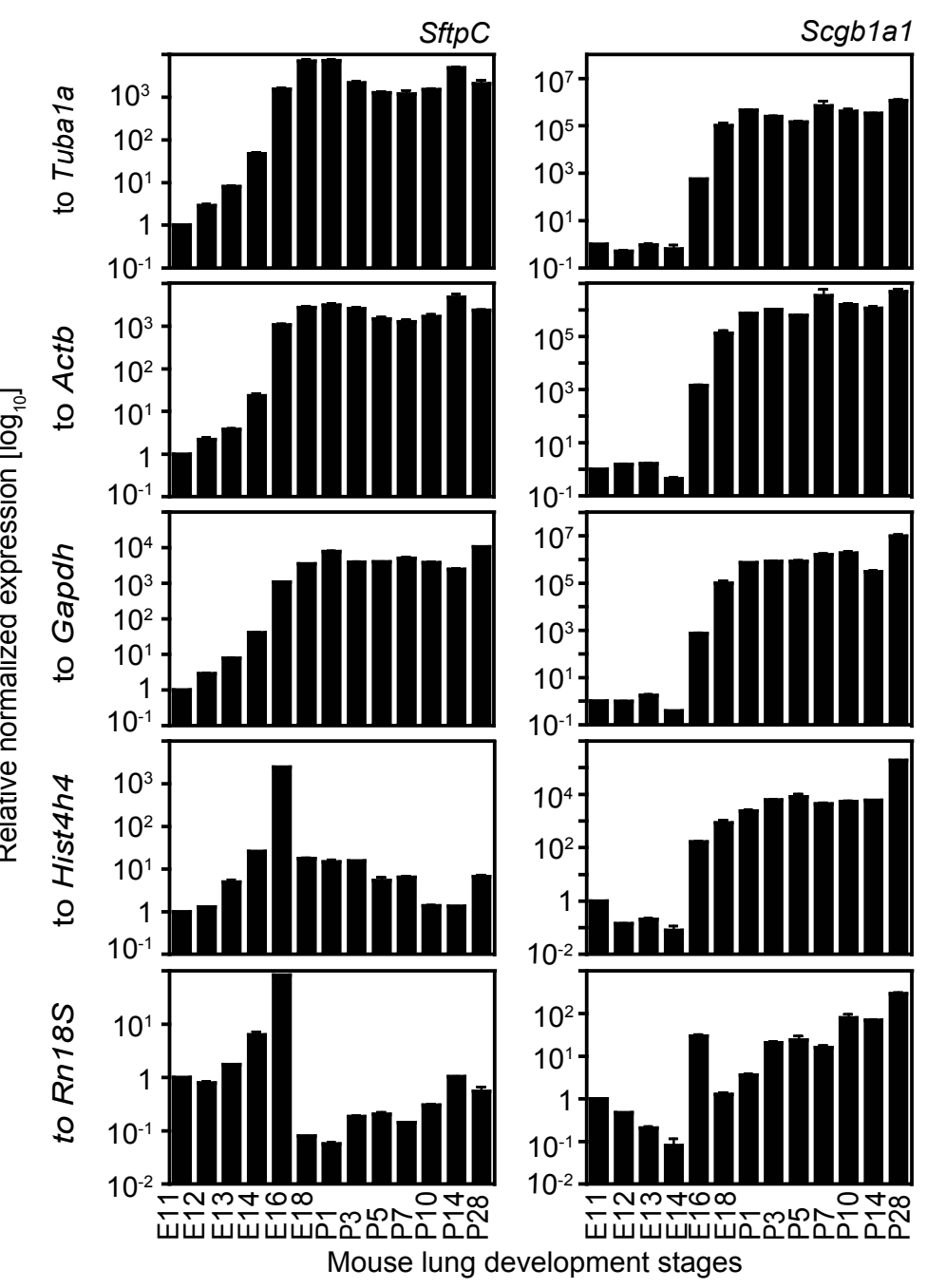

Figure 6. Expression analysis of two cell lineage markers during mouse lung development using different reference genes for normalization. Expression of surfactant protein $\mathrm{C}$ (SftpC, left) and Clara cell-specific $10 \mathrm{kDA}$ protein (Scgblal, right) was analysed during lung development by qRT-PCR. Expression analysis in all stages of lung development was normalized to each of the five reference genes, Tubala, Actb, Gapdh, Hist4h4, and Rn18S. Days post coitum, $E$; postnatal, $P$. Data are represented as mean $\pm \mathrm{SD} ; n=3$. 


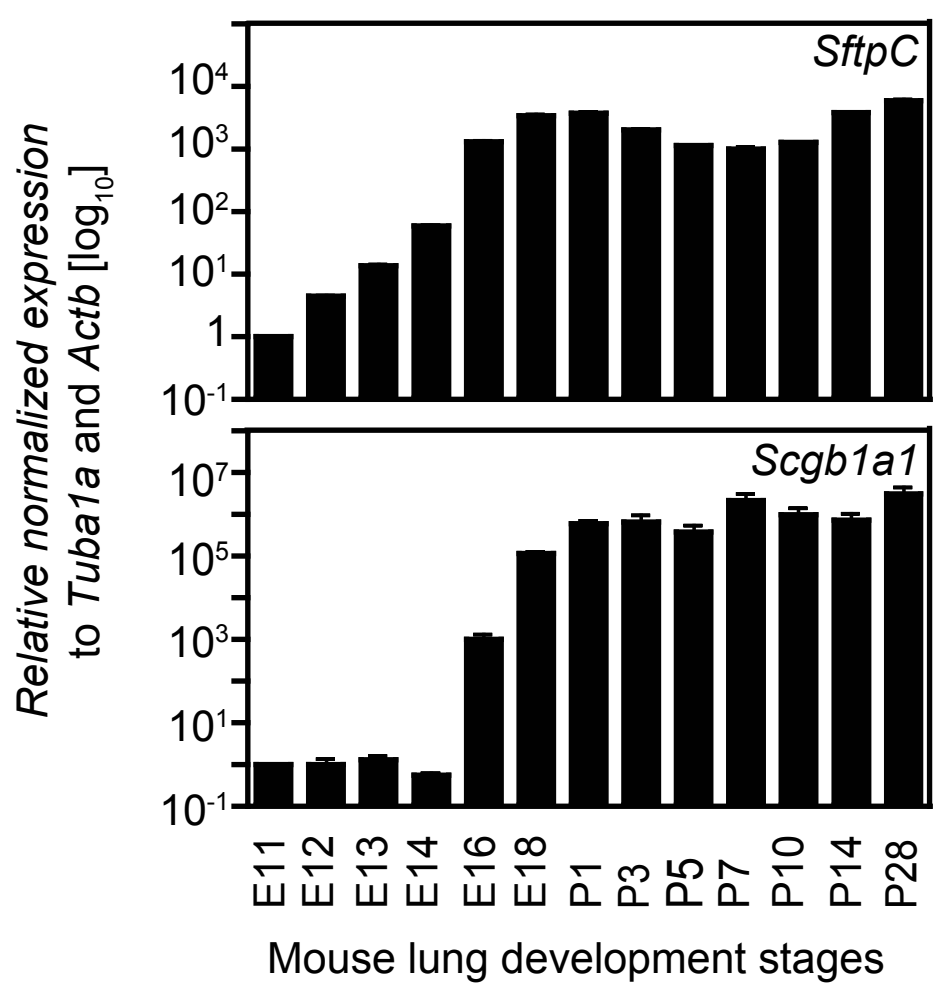

Figure 7. Expression analysis of two cell lineage markers during mouse lung development using a combination of two reference genes for normalization. Expression of surfactant protein $\mathrm{C}(\mathrm{SftpC})$ and Clara cell-specific $10 \mathrm{kDA}$ protein $(\mathrm{Scgblal})$ was analysed during lung development by qRT-PCR. Expression analysis in all stages of lung development was normalized to both Tubala and Actb. Days post coitum, E; postnatal, P. Data are represented as mean $\pm \mathrm{SD} ; n=3$.

\section{Discussion}

One of the most critical aspects of relative quantification of gene expression by qRT-PCR is normalization. In an ideal situation, transcript numbers are normalized and corrected after cell numbers. However, it is not always feasible to count cells. Alternatively, it is also possible to normalize with respect to the RNA quantity used for the reverse transcriptase reaction. However, both methods do not account for variations originated during RNA isolation, degradation during storage, cDNA synthesis and qPCR amplification. In order to circumvent these problems, it is recommended to normalize gene expression to an internal control, for example a "spike-in" standard or a reference gene whose expression is not affected by the conditions tested during the experiment. Due to historical reasons, the most commonly used reference genes for normalization of qRT-PCR based expression analysis include Gapdh, Actb and Rn18S. However, the expression of these classical reference genes has been shown to be affected by certain experimental approaches. For instance, Gapdh is known to be involved in additional non-glycolytic pathways and is prone to show variation in mRNA amounts [27]. It has also been reported that even though transcription rate of Gapdh was similar in different tissues, they contained very different amounts of mRNA [28]. Gapdh has also been shown to have significant differences in mRNA expression across a panel of 72 human tissue samples studied, including a maximal difference of 15-fold [29]. Actb has been shown to be regulated in tumour samples, as was 
shown in different leukaemia patient tumour samples [30]. In the case of $R n 18 S$, it is widely believed that ribosomal RNA (rRNA) constitutes approximately $90 \%$ of the total RNA of the cells and it is a constant fraction of the total RNA. However, it has been shown that equal fractions of rRNA do not necessarily ensure equal fractions of mRNA [31]. Further, it has been shown that while, the sum total of $28 \mathrm{~S}, 18 \mathrm{~S}$ and $5 \mathrm{~S}$ rRNA remains as a constant fraction of the total RNA, there are changes in the levels of each of the individual rRNA components during development [32]. In addition, it has been demonstrated that expression of rRNA genes undergoes considerable tissue specific variation, with increased expression in tissues containing a large proportion of proliferating cells (stem cells, foetal stages, lymphoid tissues, neoplastic tissues) and in tissues specialized in exocrine protein secretion (e.g., salivary glands) [33,34]. Additionally, rRNA expression increased after viral infections [35]. These observations have been explained as an increased number of ribosomes are required during cell division and protein secretion, resulting in an increased expression of rRNA genes. There are no reports of rRNA expression analysis during mouse development; however, similar observations have been made in other organisms including rats [36], zebrafish [37] and Atlantic salmon [38].Taken together, it is essential to identify suitable normalizing genes for each experimental set up.

In this study, we tested the stability of expression of five of the most commonly used reference genes during mouse lung development: Tubala, Actb, Gapdh, Hist4h4 and Rn18S. Of these five putative reference genes, Tubala was found to have the least changes in expression level in all of the sample groups (Groups 1-5) analysed here, which contained different stages of mouse lung development depending on the biological process occurring at these specific stages. Tubala gene encodes a protein, alpha-tubulin, which forms a dimer with beta-tubulin to make up the microtubules which are essential for cell division and cell movement. It has been widely used as a normalization marker during mouse development [39] as well as in cancer [40]. Our results support that Tubala can be used as endogenous control for the normalization of expression analysis during branching morphogenesis (Group 1), cellular differentiation (Group 2), pre-natal and post-natal lung development (Groups 3 and 4) and general lung development (Group 5). The groups have been divided to contain increasing heterogeneity and complexity, such that Group 5 is the most variable sample. During the course of lung development, several dramatic changes take place in the embryonic lung, including proliferation and expansion of progenitor cells, specification and subsequent differentiation of the multiple cell lineages as well the formation of the capillary network. Consequently, Group 5 includes all these stages and the resulting extensive cellular diversity and the large age-related differences, indicating that it may be necessary to divide the lung development process into different experimental groups for expression analysis.

Furthermore, several reports based on different statistical algorithms suggest the use of at least two different endogenous controls for the normalization of expression analysis to increase the accuracy and reliability of the data [31]. In our study, Tubala and Actb were found to be the most suitable, while $A c t b$ and Gapdh were the second most suitable pair of reference genes for normalization during mouse lung development. However, due to a large number of reported pseudogenes [41], Actb and Gapdh may be used with some scepticism to support and complement the results obtained after Tubala normalization. Hist4h4 and Rn18S showed the maximum variability in their expression during the different phases of mouse lung development, with a remarkable increase in their expression at later stages, supporting that they are not appropriate as internal controls for expression analysis during lung development. Our results indicate that it is essential to include validation of reference genes as an 
integral part of the experiment design. Inappropriate reference genes may have a profound influence on the results which includes divergent outcomes leading to inaccurate data interpretation.

\section{Experimental Section}

\subsection{Ethics Statement}

Mouse work was performed in compliance with the German Law for Welfare of Laboratory Animals. The permission to perform the experiments presented in this study was obtained from the Regional Council (Regierungspräsidium in Darmstadt, Germany). The numbers of the permissions are IVMr46-53r30.03.MPP04.12.02 and IVMr46-53r30.03.MPP06.12.01. Animals were killed for scientific purposes according to the law mentioned above which comply with national and international regulations. Thus, trained individuals performed all the animal work and took precautions to reduce animal suffering. As method of sacrifice, adult animals were anaesthetized using 5\% isoflurane followed by cervical dislocation. Death was confirmed by respiratory arrest and stop of heartbeat. Embryos were then isolated from the mice and kept for short time in ice cold PBS. Prior to organ micro dissection, the embryos were killed by decapitation using very sharp scalpels. Similarly, for organ isolation from postnatal mice (P1-P14), the animals were anaesthetized using 3\% isoflurane followed by decapitation before organ dissection.

\subsection{Work with Animals}

Animals were housed under controlled temperature and lighting (12/12-h light/dark cycle), fed with commercial animal feed and water ad libitum. Time pregnant C57B16 wild type mice were sacrificed on post coitum days 11.5, 12.5, 13.5, 14.5, 16.5 and 18.5 (E11-18, day of plug = E0.5) according to standard methods described above and embryos were collected. Staging was confirmed by somite numbers till E14.5, and subsequently, mouse embryos were staged morphologically. Embryonic lungs were isolated using microscopy based manual dissection using previously established protocols [42] and flash frozen in liquid nitrogen. C57B16 pups were sacrificed on day 1, 3, 5, 7, 10, 14 and 28 (P1-28, day of birth $=$ P0) and their lungs were also harvested after perfusion with PBS and flash frozen in liquid nitrogen.

\subsection{RNA Isolation, cDNA Synthesis and $q R T-P C R$}

In order to have sufficient material for RNA isolation, five lungs were used for the embryonic stages, while for post natal stages, three lungs were used. Total RNA was isolated from the lungs for using the RNeasy plus mini kit (Qiagen, Hilden, Germany), including an on-column RNase-free DNase digestion. RNA integrity was examined using agarose gel electrophoresis. RNA was quantified and purity was verified using the Nano-Drop 2000c UV-vis spectrophotometer (Thermo Fisher Scientific, Waltham, MA, USA) and $1 \mu \mathrm{g}$ of the total RNA was used for cDNA conversion using the High Capacity cDNA Reverse Transcription kit (Applied Biosystems) using random hexamers following manufacturer's instructions. cDNA samples were diluted 1:4 and $1 \mu \mathrm{L}$ of each was used in a $10 \mu \mathrm{L}$ qRT-PCR reaction using the SYBR ${ }^{\circledR}$ Green PCR Master mix (Applied Biosystems, Foster City, CA, USA) and $250 \mathrm{nM}$ each forward and reverse primers. Transcript levels were analysed on the ABI Step 
One Plus PCR machine over 40 cycles of $95{ }^{\circ} \mathrm{C}$ for $15 \mathrm{~s}$ and $60{ }^{\circ} \mathrm{C}$ for $1 \mathrm{~min}$ in a two-step thermal cycle preceded by a 10 min denaturation at $95{ }^{\circ} \mathrm{C}$. All reactions were performed in triplicate and analysis was performed using five biological replicates. Primers were designed for expression analysis for each of the genes using Geneious (Geneious version 6.1 created by Biomatters [43]). Primer characteristics, including annealing temperature, formation of primer dimers and secondary structures were checked using the jPCR [15] and the Sigma Aldrich oligo Evaluator online tool [44]. In addition, specificity of the primers was checked using the NCBI primer BLAST tool [45]. Absence of genomic DNA was confirmed by -RT reactions for all RNA pools using gene specific primers.

For the analysis of gene expression, relative amounts of both genes of interest were calculated normalized to each reference gene based on the formula, relative expression $=E^{\Delta C \mathrm{~T}}$, where $E$ represents the amplification efficiency $(E)$ for each gene and $\Delta C_{\mathrm{T}}$ is the difference in the $C_{\mathrm{T}}$ from each target sample and calibrator $\left(\Delta C_{\mathrm{T}}=C_{\mathrm{T}}\right.$ (calibrator) $-C_{\mathrm{T}}($ target $\left.)\right)$. The normalization factor, calculated using the geometric mean of the relative expression of the two reference genes selected for normalization, was used to obtain the relative normalized expression based on two reference genes simultaneously [46,47].

\subsection{Sequencing of PCR Products}

PCR products were gel purified after qRT-PCR and cloned into pJET1.2 blunt cloning vector using the CloneJET PCR cloning kit (Thermo Scientific, Waltham, MA, USA). Five clones for each gene were selected and sent for sequencing after plasmid purification. Sequence analysis was performed using Geneious (Geneious version 6.1 created by Biomatters [43]).

\subsection{Stability Ranking of Candidate Reference Genes}

For the calculation of the stability of the reference genes, the samples analysed here were combined into five experimental groups: branching morphogenesis (Group 1; E11.5-E16.5 including late embryonic and pseudoglandular phases), cellular differentiation (Group 2; E16.5-P5 including canalicular and saccular phases), pre-natal lung development (Group 3; E11.5-E18.5 including embryonic, pseudoglandular, canalicular and initial saccular phases); post-natal lung development (Group 4; P1-P28 including late saccular and alveolar phases) and general lung development (Group 5; E11.5-P28 including all phases of lung development). Reference gene validation was performed using the statistical algorithm geNorm [20]. geNorm uses a pair-wise approach, assuming that stable reference genes would have similar intergroup variation, leading to small pair wise differences. Stability is estimated by the average pair wise variation of the given reference gene with all the other genes in the validation set. Reference genes are then ranked through successive step wise exclusion of the least stable gene. Normalization factors were calculated by geometric averaging of the reference genes in a group. Subsequently, pairwise Variation $V_{n /(n+1)}$ was estimated by including stepwise reference genes until the $(n+1)$ th gene had no significant contribution to the stability of expression.

\section{Conclusions}

It is necessary to select an appropriate reference gene (ideally two) for each experimental setup as an internal control for the normalization of relative expression analysis. The ideal reference gene for a 
specific experiment is the one whose expression is not affected by the different experimental conditions tested. This analysis demonstrates that Tubala is the most suitable endogenous reference for the normalization of qRT-PCR-based expression analysis during the different phases of lung development.

\section{Acknowledgments}

We thank R. Bender, K. Goth and G. Stämmler for technical support. This work was done according to the program for competitive growth of the Kazan Federal University and the Russian Government. G. Barreto is funded by the "LOEWE-Initiative der Landesförderung" (Wiesbaden Germany) (III L 4-518/15.004 2009) and the "Deutsche Forschungsgemeinschaft" (DFG, Bonn, Germany) (BA 4036/1-1).

\section{Author Contributions}

Aditi Mehta and Stephanie Dobersch performed the experiments and analyzed the data. Guillermo Barreto, Reinhard H. Dammann, Saverio Bellusci, Olga N. Ilinskaya and Thomas Braun conceived and designed the experiments. Guillermo Barreto and Aditi Mehta wrote the manuscript. All authors have read and approved the final manuscript.

\section{Conflicts of Interest}

The authors declare no conflict of interest. The founding sponsors had no role in the design of the study; in the collection, analyses, or interpretation of data; in the writing of the manuscript; or in the decision to publish the results.

\section{References}

1. Citri, A.; Pang, Z.P.; Sudhof, T.C.; Wernig, M.; Malenka, R.C. Comprehensive qPCR profiling of gene expression in single neuronal cells. Nat. Protoc. 2012, 7, 118-127.

2. Kralj, J.G.; Salit, M.L. Characterization of in vitro transcription amplification linearity and variability in the low copy number regime using External RNA Control Consortium (ERCC) spike-ins. Anal. Bioanal. Chem. 2013, 405, 315-320.

3. Nolan, T.; Hands, R.E.; Bustin, S.A. Quantification of mRNA using real-time RT-PCR. Nat. Protoc. 2006, 1, 1559-1582.

4. Huggett, J.; Dheda, K.; Bustin, S.; Zumla, A. Real-time RT-PCR normalisation; strategies and considerations. Genes Immun. 2005, 6, 279-284.

5. Fort, P.; Marty, L.; Piechaczyk, M.; el Sabrouty, S.; Dani, C.; Jeanteur, P.; Blanchard, J.M. Various rat adult tissues express only one major mRNA species from the glyceraldehyde-3phosphate-dehydrogenase multigenic family. Nucleic Acids Res. 1985, 13, 1431-1442.

6. Costa, R.H.; Kalinichenko, V.V.; Lim, L. Transcription factors in mouse lung development and function. Am. J. Physiol. Lung Cell. Mol. Physiol. 2001, 280, L823-L838.

7. Warburton, D.; Schwarz, M.; Tefft, D.; Flores-Delgado, G.; Anderson, K.D.; Cardoso, W.V. The molecular basis of lung morphogenesis. Mech. Dev. 2000, 92, 55-81. 
8. Cardoso, W.V.; Lu, J. Regulation of early lung morphogenesis: Questions, facts and controversies. Development 2006, 133, 1611-1624.

9. Adachi, Y.; Shibai, Y.; Mitsushita, J.; Shang, W.H.; Hirose, K.; Kamata, T. Oncogenic Ras upregulates NADPH oxidase 1 gene expression through MEK-ERK-dependent phosphorylation of GATA-6. Oncogene 2008, 27, 4921-4932.

10. Erickson, H.P. Evolution of the cytoskeleton. Bioessays 2007, 29, 668-677.

11. Krasnov, G.S.; Dmitriev, A.A.; Snezhkina, A.V.; Kudryavtseva, A.V. Deregulation of glycolysis in cancer: Glyceraldehyde-3-phosphate dehydrogenase as a therapeutic target. Expert Opin. Ther. Targets 2013, 17, 681-693.

12. Kornberg, R.D. Structure of chromatin. Annu. Rev. Biochem. 1977, 46, 931-954.

13. Elsevier, S.M.; Ruddle, F.H. Location of genes coding for $18 \mathrm{~S}$ and $28 \mathrm{~S}$ ribosomal RNA within the genome of Mus musculus. Chromosoma 1975, 52, 219-228.

14. Kearse, M.; Moir, R.; Wilson, A.; Stones-Havas, S.; Cheung, M.; Sturrock, S.; Buxton, S.; Cooper, A.; Markowitz, S.; Duran, C.; et al. Geneious Basic: An integrated and extendable desktop software platform for the organization and analysis of sequence data. Bioinformatics 2012, 28, 1647-1649.

15. Kalendar, R.; Lee, D.; Schulman, A.H. Java web tools for PCR, in silico PCR, and oligonucleotide assembly and analysis. Genomics 2011, 98, 137-144.

16. Livak, K.J.; Schmittgen, T.D. Analysis of relative gene expression data using real-time quantitative PCR and the 2(-Delta Delta C(T)) Method. Methods 2001, 25, 402-408.

17. Rasmussen, R. Quantification on the LightCycler. In Rapid Cycle Real-Time PCR; Meuer, S., Wittwer, C., Nakagawara, K.-I., Eds.; Springer: Berlin/Heidelberg, Germany, 2001; pp. 21-34.

18. Bookout, A.L.; Mangelsdorf, D.J. Quantitative real-time PCR protocol for analysis of nuclear receptor signaling pathways. Nucl. Recept. Signal. 2003, 1, e012.

19. Ririe, K.M.; Rasmussen, R.P.; Wittwer, C.T. Product differentiation by analysis of DNA melting curves during the polymerase chain reaction. Anal. Biochem. 1997, 245, 154-160.

20. Vandesompele, J.; de Preter, K.; Pattyn, F.; Poppe, B.; van Roy, N.; de Paepe, A.; Speleman, F. Accurate normalization of real-time quantitative RT-PCR data by geometric averaging of multiple internal control genes. Genome Biol. 2002, 3, RESEARCH0034.

21. Dong, J.; Jiang, G.; Asmann, Y.W.; Tomaszek, S.; Jen, J.; Kislinger, T.; Wigle, D.A. MicroRNA networks in mouse lung organogenesis. PLoS One 2010, 5, e10854.

22. Perl, A.K.; Wert, S.E.; Nagy, A.; Lobe, C.G.; Whitsett, J.A. Early restriction of peripheral and proximal cell lineages during formation of the lung. Proc. Natl. Acad. Sci. USA 2002, 99, 10482-10487.

23. Perl, A.K.; Wert, S.E.; Loudy, D.E.; Shan, Z.; Blair, P.A.; Whitsett, J.A. Conditional recombination reveals distinct subsets of epithelial cells in trachea, bronchi, and alveoli. Am. J. Respir. Cell Mol. Biol. 2005, 33, 455-462.

24. Guckenberger, M.; Andratschke, N.; Alheit, H.; Holy, R.; Moustakis, C.; Nestle, U.; Sauer, O. Definition of stereotactic body radiotherapy Principles and practice for the treatment of stage I non-small cell lung cancer. Strahlenther Onkol. 2014, 190, 26-33.

25. Wert, S.E.; Glasser, S.W.; Korfhagen, T.R.; Whitsett, J.A. Transcriptional elements from the human SP-C gene direct expression in the primordial respiratory epithelium of transgenic mice. Dev. Biol. 1993, 156, 426-443. 
26. Singh, I.; Mehta, A.; Contreras, A.; Boettger, T.; Carraro, G.; Wheeler, M.; Cabrera-Fuentes, H.A.; Bellusci, S.; Seeger, W.; Braun, T.; et al. Hmga2 is required for canonical WNT signaling during lung development. BMC Biol. 2014, 12, 21.

27. Suzuki, T.; Higgins, P.J.; Crawford, D.R. Control selection for RNA quantitation. BioTechniques 2000, 29, 332-337.

28. Piechaczyk, M.; Blanchard, J.M.; Marty, L.; Dani, C.; Panabieres, F.; el Sabouty, S.; Fort, P.; Jeanteur, P. Post-transcriptional regulation of glyceraldehyde-3-phosphate-dehydrogenase gene expression in rat tissues. Nucleic Acids Res. 1984, 12, 6951-6963.

29. Barber, R.D.; Harmer, D.W.; Coleman, R.A.; Clark, B.J. GAPDH as a housekeeping gene: Analysis of GAPDH mRNA expression in a panel of 72 human tissues. Physiol. Genomics 2005, 21, 389-395.

30. Dighiero, G.; Intrator, L.; Cordonnier, C.; Tortevoye, P.; Vernant, J.P. High levels of anti-cytoskeleton autoantibodies are frequently associated with chronic GVHD. Br. J. Haematol. 1987, 67, 301-305.

31. Solanas, M.; Moral, R.; Escrich, E. Unsuitability of using ribosomal RNA as loading control for Northern blot analyses related to the imbalance between messenger and ribosomal RNA content in rat mammary tumors. Anal. Biochem. 2001, 288, 99-102.

32. Bilodeau-Goeseels, S.; Schultz, G.A. Changes in ribosomal ribonucleic acid content within in vitro-produced bovine embryos. Biol. Reprod. 1997, 56, 1323-1329.

33. Wisnieski, F.; Calcagno, D.Q.; Leal, M.F.; dos Santos, L.C.; Gigek Cde, O.; Chen, E.S.; Pontes, T.B.; Assumpcao, P.P.; de Assumpcao, M.B.; Demachki, S.; et al. Reference genes for quantitative RT-PCR data in gastric tissues and cell lines. World J. Gastroenterol. 2013, 19, 7121-7128.

34. Thorrez, L.; van Deun, K.; Tranchevent, L.-C.; van Lommel, L.; Engelen, K.; Marchal, K.; Moreau, Y.; van Mechelen, I.; Schuit, F. Using Ribosomal Protein Genes as Reference: A Tale of Caution. PLoS One 2008, 3, e1854.

35. Tanaka, S.; Furukawa, T.; Plotkin, S.A. Human cytomegalovirus stimulates host cell RNA synthesis. J. Virol. 1975, 15, 297-304.

36. Bonefeld, B.E.; Elfving, B.; Wegener, G. Reference genes for normalization: A study of rat brain tissue. Synapse 2008, 62, 302-309.

37. McCurley, A.T.; Callard, G.V. Characterization of housekeeping genes in zebrafish: Male-female differences and effects of tissue type, developmental stage and chemical treatment. BMC Mol. Boil. 2008, 9, 102.

38. Olsvik, P.A.; Lie, K.K.; Jordal, A.E.; Nilsen, T.O.; Hordvik, I. Evaluation of potential reference genes in real-time RT-PCR studies of Atlantic salmon. BMC Mol. Biol. 2005, 6, 21.

39. Dummler, B.; Tschopp, O.; Hynx, D.; Yang, Z.Z.; Dirnhofer, S.; Hemmings, B.A. Life with a single isoform of Akt: Mice lacking Akt2 and Akt3 are viable but display impaired glucose homeostasis and growth deficiencies. Mol. Cell. Biol. 2006, 26, 8042-8051.

40. Mendoza-Villanueva, D.; Deng, W.; Lopez-Camacho, C.; Shore, P. The Runx transcriptional co-activator, CBFbeta, is essential for invasion of breast cancer cells. Mol. Cancer 2010, 9, 171.

41. Sun, Y.; Li, Y.; Luo, D.Z.; Liao, D.J. Pseudogenes as weaknesses of ACTB (Actb) and GAPDH (Gapdh) used as reference genes in reverse transcription and polymerase chain reactions. PLoS One 2012, 7, e41659. 
42. Del Moral, P.M.; Warburton, D. Explant culture of mouse embryonic whole lung, isolated epithelium, or mesenchyme under chemically defined conditions as a system to evaluate the molecular mechanism of branching morphogenesis and cellular differentiation. Methods Mol. Biol. 2010, 633, 71-79.

43. Geneious. Available online: http://www.geneious.com (accessed on 10 November 2013).

44. OligoEvaluator ${ }^{\mathrm{TM}}$. Available online: http://www.sigmaaldrich.com/life-science/custom-oligos/customdna/learning-center/calculator.html (accessed on 10 November 2013).

45. Primer-BLAST. Available online: http://www.ncbi.nlm.nih.gov/tools/primer-blast/ (accessed on 10 November 2013).

46. Hellemans, J.; Mortier, G.; de Paepe, A.; Speleman, F.; Vandesompele, J. qBase relative quantification framework and software for management and automated analysis of real-time quantitative PCR data. Genome Biol. 2007, 8, R19.

47. Figueiredo, A.; Loureiro, A.; Batista, D.; Monteiro, F.; Varzea, V.; Pais, M.S.; Gichuru, E.K.; Silva, M.C. Validation of reference genes for normalization of qPCR gene expression data from Coffea spp. hypocotyls inoculated with Colletotrichum kahawae. BMC Res. Notes 2013, 6, 388.

(C) 2015 by the authors; licensee MDPI, Basel, Switzerland. This article is an open access article distributed under the terms and conditions of the Creative Commons Attribution license (http://creativecommons.org/licenses/by/4.0/). 